\title{
Implementing Differentiated Instruction in EFL Remedial Classes: An Action Research
}

\author{
Ozma Siddiqui \\ English Language Institute, King Abdulaziz University \\ E-mail: ozma_siddiqui@hotmail.com \\ Fatimah M. A. Alghamdi (Corresponding author) \\ English Language Institute, King Abdulaziz University \\ P O Box 42702, Jeddah 21551, Saudi Arabia \\ E-mail: fmalghamdi@kau.edu.sa
}

Received: August 20, 2017 Accepted: October 8, 2017 Published: October 10, 2017

doi:10.5296/elr.v3i2.11726 URL: http://doi.org/10.5296/elr.v3i2.11726

\begin{abstract}
Since English language teaching became a compulsory part of the curriculum in all institutes of higher education in Saudi Arabia, different syllabi and teaching methodologies have been experimented to help adult students learn the language effectively, particularly within first-year university preparatory programs. However, despite the huge efforts in aiding the educational process of English as a foreign language (EFL), there is a large turnout of students not meeting the criteria needed to pass their preparatory year. As students are enrolled in one EFL program with the same textbook and are expected to achieve the same benchmarks, there has arisen a need to reexamine the mode in which the curriculum is being delivered. The way forward seems to be remedial intervention that addresses the inadequacies of the non-progressing learners, and utilizes an instructional approach that modifies material and instruction to meet learners' individual needs. The approach which takes into account individual differences has been known amongst educationalists as Differentiated Instruction (DI). This action research investigation seeks to explore DI as it is being implemented at an EFL remedial program, its procedures and outcomes. We hypothesize that students would benefit from the varied instruction, modified materials and flexible grouping within the class setup. Quantitative data was collected in the form of the grades of a pretest and a posttest. The differences in the results of the two sets of tests showed positive impact of implementing
\end{abstract}


DI on learning, and were found to be statistically significant. Also, tutors' opinions were sought through a mini questionnaire consisting of open-ended questions. It is hoped that the action research thus conducted will contribute to answering pertinent questions and benefit the EFL remedial practice as well as future studies.

Keywords: EFL learners, Remedial intervention, Differentiated instruction

\section{Introduction}

Students at the Saudi university where this study is conducted are enrolled in the preparatory year program after high school. The program consists of 18 hours a week of intensive instruction in English as a foreign language (EFL). Students are taught the four skills of reading, writing, speaking and listening with recourse to both the traditional whole class method and with the use of technology and other interactive platforms.

Following a placement test, students are enrolled into one of the proficiency levels of B, B1, $A$ and A1 of the Common European Framework of Reference for Languages (CEFR). Initially, students seem to be suited to the level they are placed in, "but, as they progress through the modules, some of them begin to fall behind and are unable to cope with the curriculum. It follows that a large number of failures have become a regular occurrence" as the course advances (Alghamdi \& Siddiqui, 2016, p. 204).

English language educationalists of both secondary and tertiary backgrounds often note that teaching English as a foreign language (EFL) has long been influenced by the grammar translation method which was recognized for its academic merits. But rising concerns about the method, which did not appear to lead to learners learning the language itself and only learn about it, paved the way for the more hands-on communicative language teaching (CLT) approach. Interest in the merits of the CLT approach first emerged in the late 1960s (Teflpedia.com, 2017).

However, despite the technology equipped classrooms and other aids, large numbers of students in the college preparatory year do not attain the desired success and pass the criteria required for them to enter their majors. As students continue to experience problems with passing the intensive English program at the preparatory year and require additional academic support, the university has made provision for extra tuition in the form of remedial classes. In a previous study, Alghamdi and Siddiqui (2016) identified remedial tutors' patterns of teaching and linked it to students' expectations. They found out that remedial sessions' teachers are often involved in teaching strategies that are characterized with simplified instruction, repeated content and slow pace of instruction. These characteristics were found to have close resemblance with teaching strategies often associated with Differentiated Instruction (DI). DI is a teaching approach that advocates modifying content and varying instruction to meet individual learners' needs and interests (Tomlinson, 2000).

In another study at the same context of this study, Alghamdi and Alnowaiser (2017), found out that DI strategies were used amongst the teachers of regular EFL classrooms to address individual differences amongst learners. However, the impact of implementing these strategies in the classroom was not measured. The aim of this research is therefore to see how a DI model can be designed specifically for remedial intervention, and whether it can be applied in a manner which would benefit students. In addition, the study's purpose is to 
observe how DI strategies in EFL remedial sessions can impact students' achievement.

\section{Research Questions}

The aim of this paper is to explore the procedures of implementing DI strategies in EFL remedial teaching at a Saudi university, and find its outcomes. We, therefore, aim at answering two questions:

RQ1 What does a DI model specifically designed for remedial intervention include, and how does it work?

RQ2 How does implementing DI strategies in EFL remedial sessions impact students' achievement?

\section{Literature Review}

So far, the CLT approach has found favor with Arab learners as it focuses on the language used in real situations. In a country which hosts thousands of visitors on religious visits from English speaking nations, the CLT approach is considered to be particularly significant. According to Alwazir and Shukri (2017) CLT is effective because communication the key purpose of language and improving communicative competence central to EFL teaching.

At institutional level, CLT has been the preferred approach to teaching. The Saudi Ministry of Education's manual for teaching English clearly states that

The aim of teaching English in the secondary schools is to have the pupil attain a standard which will permit him [sic.] to make ready use of desired materials in English and which will enable him [sic.] to communicate satisfactorily, according to his [sic.] needs, in both spoken and written forms (MoE 2002, cited in Mahboob \& Elyas, 2014, p. 129).

In recent years however, EFL practitioners have raised questions about the CLT approach and suggested that it could be complemented with other approaches. Littlewood (2013) in his paper "Developing a Context-Sensitive Pedagogy for Communication-Oriented Language Teaching" recommends COLT, Communicative Oriented Language Teaching, in place of CLT. In COLT the learning process is staged in gradual steps towards language competency, and the aim is no longer to find the best teaching method but to "clarify principles by which each teacher can develop an approach which is sensitive to his or her own specific context," (Littlewood, 2013, p. 9).

Most classrooms contain students of mixed abilities. Some may struggle with their learning while others seem to breeze through and achieve the expected milestones. Still others and usually a fair majority are somewhere in between. Students also have different interests and sometimes learn in different ways. The theory of different learning styles is often thought to have an impact in EFL environments although it is equally relevant to all teaching contexts. In order for all students to learn optimally, teachers can use differentiated instruction.

Differentiation recognizes individual differences and is particularly conducive to motivation with regards to low achievers. "At its most basic level, differentiation consists of the efforts of teachers to respond to variance among learners in the classroom" (Tomlinson, 2000).

EFL practitioners contest that due to the variance in students' approaches to learning, 
different students learn differently giving support to the theory of multiple intelligences (MI) (Gardner, 1983, cited in McCarthy, 2014). MI is based on the surmise that some strategies simply work better for certain students than others and that learning profiles help to determine students' learning preferences thereby allowing teachers to design their teaching around them (McCarthy, 2014).

Differentiation can occur at three levels: differentiating for content or what the student needs to learn and how he will access that information; differentiating for process - the actual activities or tasks the student does to master the content; and differentiating for the products which the student engages in, such as projects he is expected to do which call for extending his learning (Tomlinson 2000). Tomlinson and Allan (2000) in their book 'Leadership for Differentiating Schools \& Classrooms' present a concept map for differentiating instruction for content, process and product. They also added differentiating the learning environment, i.e. how the classroom can be arranged to facilitate optimal learning.

Strategies used for differentiated instruction include tasks which excite inquiry such as unfamiliar vocabulary where students need to use word association, context and visuals to guess the meaning. Such kinds of tasks give students a sense of ownership for their learning. When students begin to own the learning process, differentiation occurs naturally (Raffaelli, 2014).

According to Doolittle (1997), Vygotsky's, the Russian psychologist, theory of the zone of proximal development (ZPD) has led to the current notions about communicative language teaching. ZPD has gained currency in the context of language learning and acquisition. The theory takes into account the concept of cooperative learning, students' learning in groups, with the surmise that social interactions with other more knowledgeable peers or adults eventually help to develop more advanced mental functions such as language and problem-solving skills.

Differentiated Instruction (DI) draws on this theory, where students of a level are attended to in pairs or in small groups. The comfort zone thus created allows for a lower affective filter (Krashen, 1982) which reduces students' anxiety, generates self-esteem and increases motivation. The lower affective filter allows for greater comprehensible input which students can process to acquire language.

\section{Methods}

The study took place within a remedial teaching program administered to support low-achieving students, in a Saudi university's EFL preparatory program. Four remedial support teachers and 17 students participated in the study. The total duration of the study was 10 weeks.

While all students can benefit from differentiated instruction (DI), the approach was deliberately attempted with low-achieving students who appear for remedial sessions at the preparatory EFL program at this university. Low achievers are those who had been identified as having difficulties with the curriculum and generally unable to keep pace with their peers. The low achievers were first identified through a pretest which acted as a diagnostic tool and contained questions on grammar and vocabulary. A total of 17 low achievers formed the sample for this action research. The items were graded from a raw mark of 20 in Modules 2 
and 3. The material was selected from the current course books with the premise that students for a certain level had mastered the items already. A benchmark of 50\% and below was set as the cut-off to determine a low achiever. A previous study on remedial teaching (Alghamdi \& Siddiqui, 2016) highlighted the implementation of DI as it was being carried out at this context: "Remedial teaching in this case study was found to operate within a model where DI is playing an instrumental role. Differentiation was achieved through three main strategies: repetition, use of the Arabic language and use of simpler learning material" (p. 211). Accordingly, the authors decided (1) to work on deliberately implementing DI strategies in the remedial classroom and (2) to measure its impact on the learning of remedial sessions' clients. The present investigative enquiry, therefore, was done through an action research. Action research is an investigation method whereby a teacher researcher identifies a problem, attempts to address it through a teaching method that had gained recognition in the related literature, and measures its effect. Chamot et al (1998) defines it as:

... classroom-based research conducted by teachers in order to reflect upon and evolve their teaching. It is a systematic, documented inquiry into one aspect of teaching and learning in a specific classroom. The purpose of teacher research is to gain understanding of teaching and learning within one's classroom and to use that knowledge to increase teaching efficacy/student learning" (p. 1)

In order to answer the first research question (RQ1): What does a DI model specifically designed for EFL remedial intervention include and how does it work, the authors provided one half-day training session to the remedial classes' teachers wherein they were introduced to DI as a teaching approach. An action plan was proposed to deliberately introduce DI strategies into the remedial sessions in the second and third modules of the academic year. The focus was on three DI strategies: varied instruction, differentiated content and flexible grouping.

A total of four EFL tutors participated in the study. They worked on differentiating worksheets, modifying the prompts or stem to make understanding of concepts easier. During the remedial sessions, they varied instruction and implemented flexible grouping. Arabic was used particularly for explicit instruction and to explain vague grammatical concepts. The first language was also used for unfamiliar vocabulary or idiomatic phrases. Visual aids, realia and YouTube videos were used where possible. There were 17 female participants in all from the pre-intermediate level who sat for both the pretest and posttest in a study which was done across two modules (Modules $2 \& 3$ ). Each module consists of eight weeks of one academic year. Students, all in the age range of 18-20, were placed in small groups or pairs within and outside class time where differentiated instruction took place.

The tutors were then asked to response to an open-ended mini-questionnaire to follow their progress and elicit their perception about the implementation of differentiation in the remedial sessions. Teachers responses to the questions were then analyzed and compiled around the three DI strategies of this action research, i. e. varied instruction, differentiated material and flexible grouping. The questionnaire provided a qualitative account of the process of implementing DI strategies in the EFL remedial sessions.

The second research question (RQ2): How does implementing DI strategies in EFL remedial 


\section{Macrothink}

sessions impact students' achievement, was addressed by comparing the pretest and posttest of the remedial session students. The SPSS (Statistical Package for Social Studies, version 20.0) was used to find out if there was a significant statistical difference between the mean scores of the pretest and the posttest. Specifically, the paired sample t-test was used to see if the mean difference between the paired scores of the pretest and posttest for each set of scores was significantly different from zero.

\section{Data Analysis}

Our initial hypothesis was that implementing strategies of differentiated instruction (DI) could positively impact students' progress attending the remedial sessions. We attempted at implementing teaching strategies with a DI approach in the remedial sessions. An open-ended questionnaire was distributed amongst the tutors to register their experience of differentiated instruction.

\subsection{Implementing DI in EFL Remedial Teaching}

The open-ended questionnaire allowed the tutors to answer as fully as possible their experience of DI. The questions, listed in Table 1, focused on three main themes: varied instruction, modified tasks/material and flexible grouping. The participants providing the data will be referred to as Participant A, B, C, and D.

Table 1. Open-ended Questionnaire on tutors' perceptions of delivering DI to low achievers

1 How did you ensure that students will access the tasks you set? (visuals, data show, board work, games, etc.)

2 What specific tasks/material did you set to help students master the content? (grammar $\&$ vocabulary exercises, reading passages outside the course, etc.)

3 What tasks/material if any did you set outside the classroom to help students extend their learning? (project work, etc.)

4 How did you modify the classroom seating arrangement to facilitate learning?

5 How do you think this sort of differentiation benefits students under your tutorship?

$6 \quad$ Note any challenges you faced regarding the delivery of content, tasks set or the seating plan?

\subsubsection{Varied Instruction}

Participants A and D used different kinds of instruction and aids including the white board and electronic visuals from Google to explain vocabulary, and the data-show projector to put up worksheets, while Participant B used games. Participant $\mathrm{C}$ relied heavily on explicit instruction with explanations in Arabic to help students understand grammatical concepts. Participant $\mathrm{B}$ also used the direct approach and explained difficult concepts using the white board. Participant $C$ felt that close monitoring helped retain student attention and engagement with the tasks. Participant A was the only one who reported using varied questioning 
techniques to elicit the desired responses.

\subsubsection{Differentiated Material}

Participants A and D had students practice with simplified worksheets and handouts particularly for grammar and writing practice. Some worksheets were given as homework and followed up with in the next remedial session. Participants D reported that

Some students needed more help in grammar and vocabulary. Other students needed assistance in reading and writing. So, I gave them differentiated instruction. I made two groups and distributed various worksheets according to their areas of difficulty. Worksheets contained some grammar and vocabulary content, some worksheets were about reading comprehension. It was task based learning according to students 'needs.

Tutors also set work outside the classroom to extend the knowledge gained in the classroom and to enhance mastery of concepts. There was use of mobile apps such as Whatsapp which proved hands-on and interactive keeping students engaged with the exercises. It also provided a direct link to the tutor from home. However, Participant D did not find this useful:

I gave them some homework initially but unfortunately, none of them completed it outside the class. They always came up with some kind of excuse. I tried giving them some "links" on WhatsApp to practice grammar. They were like short quizzes to reinforce the taught concepts but I didn't receive any response from them. Therefore, I did everything in the class and stopped giving them home assignments.

Participant B reported success with online quizzes and the blackboard systems, while participant A referred students to online links. Participant $\mathrm{C}$, on the other hand, stuck to the conventional use of worksheets of different kinds with a number of standalone grammar and vocabulary exercises which were followed up with direct and explicit feedback. Participant D thought that the students needed to read more and gave handouts for their level and below:

Students found the vocabulary hard which made the reading passage difficult to understand. I had to use basic Arabic translations and also applied the Google translate app to help them understand. If students can read more, they will be able to understand more vocabulary in context and by association. (Participant D)

\subsubsection{Flexible Grouping}

A number of different arrangements were experimented with for these remedial sessions. At least one tutor reported that the chairs in her classroom were fixed to the floor so she had to make certain modifications.

Since the seats are fixed in my classroom nothing much could be done about the seating arrangement. Instead, the students who were taking extra classes were brought nearer so that they could do pair work and group work. The teacher's chair was dragged near the students to avoid the formality of regular classroom and to help students benefit from individual attention. (Participant B)

Participant D had a number of low achievers, so she used different strategies flexibly within 
the classroom. She reported that

Some students were reluctant to stay in the class during their break time, so, I gave them work from 11 to 12 in class. I made different groups and distributed material to the whole class. Students feel embarrassed if they are treated differently in the class. So it's important to make them feel comfortable. Sometimes, a few students stayed back from 12 to 1 session, so I taught them during break and gave them extra material during that time.

Tutors generally thought that flexible grouping organized at the tutor's discretion enhanced students' learning. Participant B reported:

I sometimes set students to work with peers who manifest the same academic needs. In other situations, students were randomly distributed. Sometimes low achievers were paired with high level students.

Both Participants $\mathrm{B}$ and $\mathrm{C}$ experimented with placing high achievers with low performing students in pairs instead of in groups thereby creating a comfort zone for optimal learning to take place.

Participant A decided to have students change their seats once or twice a week to allow for greater interaction with other students while Participant B felt that pair work or small groups of three worked best for DI.

\subsection{The Impact of DI Strategies on Students' Achievement}

In order to answer the second research question (RQ2), a null hypothesis was formulated:

$\mathrm{H} 0$ : There is no significant impact of implementing DI strategies in EFL remedial sessions on students' achievement.

The quantitative data was collected from students who were identified as low achievers by virtue of not having scored 50 percent on the pretest or being borderline cases. The students were all studying EFL at the preparatory program, and were of the pre-Intermediate level. The qualitative data in the form of a questionnaire was taken from the tutors who are also regular members of the faculty and teach EFL across all levels. The questions focused mainly on the procedures of the DI as they had implemented it and their perceptions and experience.

Table 2 provides information about the pretest and the posttest. There is a significant increase in the mean scores $(81.3 \%)$ of the posttest following remedial intervention. The standard deviation in the posttest, however, is higher which indicates that DI can have a significant impact on the overall scores.

Table 2. Statistics of the pretest and posttest

\begin{tabular}{llllll}
\hline & $\mathrm{N}$ & Minimum & Maximum & Mean & Std. Deviation \\
\hline Pretest & 17 & 5.00 & 11.00 & 8.1765 & 1.91165 \\
Posttest & 17 & 9.00 & 20.00 & 14.8235 & 2.48081 \\
Valid N (listwise) & 17 & & & & \\
\hline
\end{tabular}




\section{Macrothink}

Table 3 below shows that the improvement in the test scores after the remedial intervention is statistically significant. Independent sample t-test outcome shows that the difference between the two test scores is significant $(\mathrm{t}=-10.746, \mathrm{p}>0.05)$.

Table 3. Paired samples t-test

Paired Differences

\begin{tabular}{|c|c|c|c|c|c|c|c|c|c|}
\hline & & Mean & $\begin{array}{l}\text { Std. } \\
\text { Deviation }\end{array}$ & $\begin{array}{l}\text { Std. } \\
\text { Error } \\
\text { nMean }\end{array}$ & $\begin{array}{l}95 \% \\
\text { Interval } \\
\text { Difference } \\
\text { Lower }\end{array}$ & $\begin{array}{l}\text { Confidenc } \\
\text { of th } \\
\text { Upper }\end{array}$ & e & $\mathrm{df}$ & $\begin{array}{l}\text { Sig. } \\
\text { (2-tailed) }\end{array}$ \\
\hline Pair 1 & $\begin{array}{l}\text { Pretest } \\
\text { Posttest }\end{array}$ & -6.64706 & 2.54807 & .61800 & -7.95715 & -5.33696 & -10.756 & 16 & .000 \\
\hline
\end{tabular}

Figure One below further illustrates the increase in the test scores after the remedial intervention. In the posttest, the students achieved higher mean scores than their scores before the intervention.

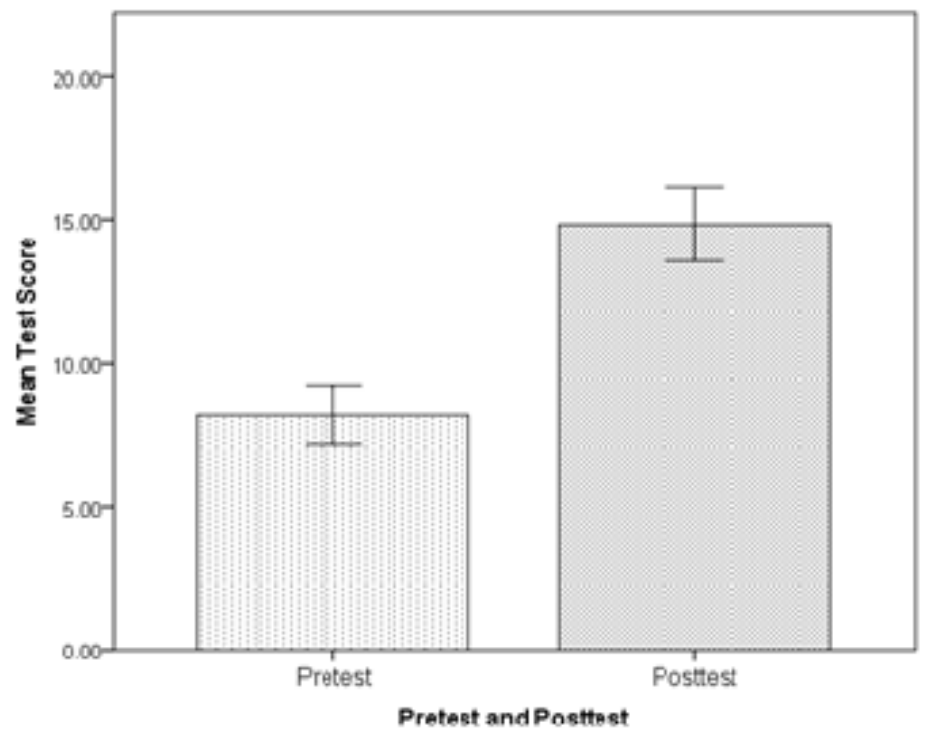

Figure 1. Mean scores of pretest and posttest

Statistical analysis indicates that DI strategies in EFL remedial teaching had a positive impact on students' achievement, and so the null hypothesis is rejected.

\section{Discussion}

Nearly all tutors agreed that visual aids and explicit teaching was successful with low achievers. The general view of DI as reported by one participant was that the method "enhances the scope of learning by providing students exposure to a variety of language", 


\section{$\triangle$ Macrothink}

Participant C.

The pretest which also worked as a diagnostic tool to identify low achievers was the first step in analyzing learner needs and designing the necessary resources, materials and instruction around these needs. Low achievers were also given the liberty to do whichever task they chose making the learning experience less of a chore.

With reference to the first research question as to the constitution of a differentiating model, it was discovered that tutors differentiated on three levels: differentiating for content by selecting those items which would figure prominently in the exams frequently resorting to the native language (Arabic) for explanations and clarifications; differentiating for grouping where tutors taught students one on one, in pairs or small groups and differentiating for pacing with tutors teaching at a slower pace than the control group. The tables show significant improvements in the scores of the pretests and posttests indicating that this was a successful differentiating model.

As regards the second research question for the study: Would differentiating for content yield higher scores than teaching directly from the student's course book, it is again evident from the results of the pretests and posttests that stressing those items which may be tested on, going at a slower pace and resorting to Arabic worked well in this context.

Another important observation emerging from the study was that instruction in individual, pairs or small groups increased motivation and improved self-esteem as students were less inhibited in these settings. This trend has been observed in another study where it was noted that "students seek out the remedial classes for a supportive environment, where input is delivered at a significantly slower pace and repeated as many times as needed without fear." (Alghamdi \& Siddiqui, 2016, p. 210).

\section{Challenges and limitations}

While there is a general inclination to incorporate DI in teaching environments to benefit all, in this case study, the social dynamics of applying it to mainstream classes, proved challenging. Students who are treated differently might feel embarrassed so it was important for tutors to ensure that they felt comfortable enough to take the extra support. According to one of the participants (Participant D):

The greatest challenge is to motivate the students to do better with more practice... some students lose interest as the course is too long and tedious for the slow learners.

Low achieving students usually suffer from low self-esteem. As a result, some students did not appear for the remedial sessions at all. Tutors therefore were also saddled with the additional task of counseling and persuading these students to attend the sessions. Generally, low achievers demonstrate a number of characteristics which are evident in their attitude to learning; "they demonstrate a weak knowledge base; have under-developed skills and poor-problem solving abilities.

However, this paper proves that the importance of tutoring programs such as remedial sessions cannot be denied and studies have indicated that they have had a large impact on students at risk of failure. 
Perhaps the biggest challenge was the lack of personal responsibility on the part of low achieving students as they demonstrated carelessness in completing work at home. They also felt stigmatized due to the attention they are being and were embarrassed about having to attend extra classes. As these lessons were being given during class time, tutors reported having difficulty in keeping up with the curriculum Pacing Guide for the mainstream class and teaching low achievers simultaneously. There was also an issue of time constraints and the fast pace of the curriculum, particularly for low achievers.

\section{Implications and Recommendations}

Studies indicate that there is a need to institutionalize diagnostic testing tools such as the pretests to identify low achievers early on in the academic module following their registration to their respective levels after the unified Placement Test. It is now clear from the above that performance levels of low achievers can be improved through intensive 'pull-out' instruction which may in our case, be effected by remedial sessions, Rennie (1993). The pretests need to be followed up with posttests to check if learners have gained mastery of the learned items. It can be concluded that the programs which are most effective, are those that answer to students' individual needs and where direct instruction is adapted to those needs and matched to students' readiness levels (Rennie, 1993). Although Jeanne Rennie advocates programs for ESL learners, they are equally applicable to EFL learners.

Differentiated Instruction is a relatively new concept in practice although in theory it has been the favored approach for decades. There have been many advocates in EFL teaching for DI such as McCarthy (2014), Raffaelli (2014) and Tomlinson (2000) to name a few and with this awareness, teachers now incorporate some aspects of DI into their classrooms whether it is by varying instruction, modifying materials or classroom management.

Based on tutors' experience with DI in this case study, it is felt that more training and experience with the technique will be helpful. It was also important to raise motivational levels and to encourage learners to be responsible for their learning.

According to one tutor, DI is beneficial for students if they are willing to be regular with their remedial sessions. This will help tutors to identify students' weak areas, prepare individualized worksheets and enable students to access help whenever required.

Tutors reported that they had the greatest success with regards to flexible grouping and differentiating for content. It is generally agreed that differentiated tasks are both interesting and engaging motivating students to understand important concepts and skills.

Conclusions

The study clearly indicates that the most success was gained from differentiating for content and materials and flexible groups. Tutors also reported some gains with differentiating for instruction. However, low achievers mainly seek one-on-one assistance so tutors generally used the direct approach with lots of explanations in the native language which is Arabic. Students also availed computer assisted instruction with the use of blackboard and interactive worksheets taken from educational websites but these were largely left to the discretion of the tutor. Students are already overwhelmed with the challenges of a new language and as websites are mainly in English, they sought help with understanding how to navigate through 
the web-based content.

Rennie (1993) suggests through research backed evidence that such programs have a number of characteristics and features which can be implemented and are effective. With the current success of remedial sessions at this university, it is thought that incorporating differentiated instruction systematically will yield better results in the performance of low achievers. If schedules can be made more flexible with a number of teachers dedicated to assisting low achievers and if the logistics of space and equipment can be resolved, the sessions can provide more than just academic support, especially with regards to raising motivation, self-esteem and more confidence in one's ability for both language acquisition and learning.

\section{References}

Alghamdi, F. M. A., \& Alnowaiser, S. A. (2017). Achieving Flex in the Inflexible: Dealing with Individual Differences in Highly Structured EFL Preparatory College Courses. English Language Teaching, 10(6), 151. https://doi.org/10.5539/elt.v10n6p151

Alghamdi, F. M. A., \& Siddiqui, O. (2016). Supporting Low-achieving EFL Learners: Expectations, Procedure and Significance of Remedial Sessions at a Saudi University. Journal of Education and Training Studies, 4(12). https://doi.org/10.11114/jets.v4i12.2028

Alwazir, B., \& Shukri, N. (2016). The Use of CLT in the Arab Context: A Critical Perspective. International Journal of English Language Education, 5(1), 15-32. https://doi.org/10.5296/ijele.v5i1.10486

Chamot, A., Barnhardt, S., Dirstine, S., \& Kevorkian, J. (1998). Conducting action research in the foreign language classroom. National Capital Language Resource Center. New York.

Doolittle, P. E. (1997). Vygotsky's Zone of Proximal Development as a Theoretical Foundation for Cooperative Learning. Journal on Excellence in College Teaching, 8(1), 83-103.

Krashen, S. (1982). Principles and Practice in Second Language (1st ed.). California: Pergamon Press.

Littlewood, W. (2013). Developing a context-sensitive pedagogy for communication-oriented $\begin{array}{lllll}\text { language teaching. } & \text { English }\end{array}$ https://doi.org/10.15858/engtea.68.3.201309.3

Mahboob, A., \& Elyas, T. (2014). English in the Kingdom of Saudi Arabia. World Englishes, 33(1), 128-142. https://doi.org/10.1111/weng.12073

McCarthy, J. (2014). How Learning Profiles Can Strengthen Your Teaching. https://www.edutopia.org/blog/learning-profiles-john-mccarthy

Morett, L. (2014). When Hands Speak Louder Than Words: The Role of Gesture in the Communication, Encoding, and Recall of Words in a Novel Second Language. The Modern Language Journal, 98(3), 834-853. https://doi.org/10.1111/modl.12125

Raffaelli, L. (2014). 18 teacher-tested strategies for differentiated instruction. Edutopia. https://www.edutopia.org/discussion/18-teacher-tested-strategies-differentiated-instruction Rennie, J. (1993). ESL and Bilingual Program Models. ERIC Digest.

Tomlinson, C. (2000). Differentiation of Instruction in the Elementary Grades. ERIC Digest.

Tomlinson, C. and Allan, S. (2000). Leadership for Differentiating Schools \& Classrooms. 


\section{Copyright Disclaimer}

Copyright reserved by the author(s).

This article is an open-access article distributed under the terms and conditions of the Creative Commons Attribution license (http://creativecommons.org/licenses/by/3.0/). 